\section{MUJERES TRAS LA CÁMARA: PANORAMA DE LAS CINEASTAS ITALIANAS DE LAS ÚLTIMAS DÉCADAS, CON UNA ENTREVISTA A LA DIRECTORA SICILIANA COSTANZA QUATRIGLIO}

\author{
Estela González de Sande \\ Universidad de Oviedo \\ gonzalezestela@uniovi.es
}

\section{WOMEN BEHIND THE CAMERA; AN OVERVIEW OF ITALIAN WOMEN FILMMAKERS IN THE LAST DECADES, WITH AN INTERVIEW WITH SICILIAN DIRECTOR COSTANZA QUATRIGLIO}

RESUMEN: La historia reciente de la cinematografía italiana cuenta con numerosas mujeres que, a pesar del escaso reconocimiento y la poca difusión de sus trabajos, han contribuido a la conformación de la diversidad y la heterogeneidad imprescindibles en cualquier disciplina artística. El desconocimiento de sus producciones da lugar a un conocimiento parcial del cine italiano contemporáneo. Así pues, este estudio pretende mostrar esa parte menos prodigada del cine a través del análisis de las principales cineastas italianas de las últimas décadas, su universo común y sus particularidades individuales. A modo de epílogo, se presenta una entrevista a la directora Costanza Quatriglio que, además de revelar las claves de su obra, nos ofrece una reflexión inédita sobre el estado actual del cine italiano y el papel de la mujer en éste.

PALABRAS CLAVE: Cine italiano, directoras, Costanza Quatriglio.

Hasta los años sesenta habian irrumpido en el mundo de la dirección cinematográfica italiana poquísimas mujeres, consideradas en el mejor de los casos mujeres transgresoras, aunque por norma eran calificadas de "extrañas" 0 , incluso, se dudaba de la autoría de sus películas -como ocurrió con Elvira Notari-. En estos años despuntaban mujeres como Liliana Cavani o Lina Wertmüller, pero el verdadero boom de las cineastas italianas comenzaría en los años setenta, en los que se produce una "feminización" del cine. Podriamos decir que esta "feminización" está intrínsecamente ligada a la conquista de poder de la mujer en la esfera pública. En el transcurso de pocos años Italia llevará a cabo una serie de reformas que impulsan esa conquista, como son las leyes que velan por la integridad de la mujer y sus derechos a nivel social. Solo en 1963
ABSTRACT: The recent history of Italian cinema includes several women directors who have contributed to the diversity and variety indispensable in any artistic discipline. However, these directors have received relatively little public recognition and the distribution of their films has been limited. The fact that production by women remains relatively unknown implies that there is only partial knowledge of contemporary Italian cinema. Therefore, this article attempts to highlight this lesser known part of this industry through the analysis of the main Italian women filmmakers of the last two decades, their common universe and individual peculiarities. An interview with director Costanza Quatriglio is also included as an epilogue. She sets out the keys to her work and offers a previously unpublished reflection on the current state of Italian film and the role of women directors in it.

KEY WORDS: Italian film, women directors, Costanza Quatriglio.

entra en vigor la ley que permite el acceso de las mujeres a todas las profesiones -a excepción únicamente de la diplomacia y del ejército-.

Sin duda, esta ley -como las sucesivas que legislan la paridad jurídica en el matrimonio, el divorcio o el abortopropician el acceso de las mujeres a la dirección cinematográfica. $Y$ así, en los años setenta encontramos varias obras dirigidas por mujeres. Son los años en que inician su actividad directoras como Giovanna Gagliardo, Liliana Ginanneschi o Edith Bruck, ${ }^{1}$ y en los que desarrollan su carrera las autoras Wertmüller y Cavani.

Más prolíficos son los años ochenta, cuando llegan a la gran pantalla las primeras películas de Cristina y Francesca 
Comencini, de Francesca Archibugi, de Gabriella Rosaleva, de Antonietta de Lillo, de Claudia Florio o de Fiorella Infascelli, entre otras. A ellas se suman otras muchas mujeres que, a pesar de no haber sido expuestas en las salas de Italia, realizan trabajos de dirección en otros medios -como la televisión- 0 inician sus primeras producciones -cortometrajes, vídeos publicitarios, series y programas- tras la cámara. Ellas son: Emanuela Piovano, Simona Izzo, Gabriella Morandi, Enrica Colusso, Vanna Paoli, Marina Spada, Anna Maria Totò, Maria Martinelli o Cinzia Torrini. Todas ellas darán el salto a la gran pantalla en años posteriores.

Así pues, el período de mayor esplendor del cine femenino vendrá en los años sucesivos, en la década de los noventa y en los años dos mil. En los noventa son muchas las mujeres que firman y dirigen largometrajes. A las ya citadas, a aquellas que iniciaron su carrera en los ochenta, se suman: Roberta Torre, Anna di Francisca, Emanuela La Torre, Anna Negri, Isabella Ciarchi, Barbara Barni, Cecilia Calvi, Asia Argento, Maria Daria Menozzi, Enza Negroni, Carola Spadoni, Elisabetta Pandimiglio, Laura Muscardin, etc. $Y$ a finales de los noventa, toda una generación de cineastas, nacidas a partir de 1965, como Costanza Quatriglio, Maria Sole Tognazzi, Nina di Majo o Ilaria Borrelli, cuya producción engrosará las listas del cine italiano del siglo XXI.

De esta manera, el siglo actual comienza con un amplio repertorio de mujeres directoras, muchas de ellas ya consolidadas en el panorama cinematográfico italiano. Son los años en los que Quatriglio, Di Majo o Tognazzi desarrollan su carrera y el momento en que se presentan los mejores largometrajes de Piovano, de Claudia Florio o de Marina Spada; sin embargo, es también la época en la que se dan a conocer tanto en el cine como en la televisión nuevas directoras como Giada Colagrande, Sabina Guzzanti, Alina Marazzi o Federica Martino, testimoniando un hecho contrastado: que en la época actual el trabajo de dirección cinematográfica no entiende de sexos.

No obstante, en el mundo del cine italiano hay una serie de características que acomuna a las directoras, distinguiéndolas de sus compañeros de profesión. Se trata de un conjunto de intereses comunes, de temáticas recurrentes y objetivos compartidos, que convierte el cine femenino italiano en un espacio común -un movimiento homogéneoque acoge muchos estilos e infinidad de particularidades individuales. Así pues, podriamos afirmar que el cine de mujeres en Italia se encuadra dentro de un mismo universo cinematográfico y que éste, a su vez, comprende espacios independientes, con caracteristicas propias, que son las que hacen que el estilo de cada directora sea único.

En el universo común convergen una serie de intereses que se manifiestan en la elección temática de muchas de las directoras citadas, tales como la atención a la realidad y a temas de actualidad como la inmigración, la homosexualidad, la marginación de las clases más desfavorecidas, la sociedad capitalista, etc. Sin embargo, destaca un argumento por encima de los demás: la atención a la mujer, a sus necesidades e inquietudes, a sus problemas, a su imagen pública y privada, a sus derechos y a los cambios sociales que han permitido la igualdad.

A partir de los años ochenta, el tema de la mujer recurre con frecuencia en las pantallas italianas, gracias a la implicación y al compromiso de las directoras. La motivación por la que se enfrentan a este argumento forma parte de ese universo común de las mujeres directoras: rescatar la memoria de las mujeres y evidenciar el importante papel que han desempeñado a lo largo de la historia. Con este objetivo nace el documental de Giovanna Gagliardo, Bellissime. II Novecento dalla parte di "Lei" (2004), al que le seguirá una segunda parte: Bellissime- dal 1960 ad oggi dalla parte di "Lei" (2006). En ambos documentales, la directora se propone contar la historia de las mujeres durante el siglo XX y el largo camino recorrido durante los últimos años en aras de la autonomía y la igualdad.

Alina Marazzi se centra en los años setenta en Vogliamo anche le rose, documental estrenado en 2008, mostrando la evolución de la mujer en esa etapa, época de reivindicaciones feministas. Marazzi dirige su teleobjetivo a tres mujeres que no se conocen entre ellas, habitantes de distintas ciudades de Italia. Sin embargo, ajenas a sus inquietudes comunes, simbolizarán la lucha de la mujer por alcanzar la paridad. Son mujeres que han vivido en la década de los sesenta y los setenta, que han sufrido las imposiciones de la cultura patriarcal, pero, conscientes del nuevo rumbo de la sociedad, han sido capaces de rebelarse, afirmando su autonomía. Tres mujeres son también las protagonistas de Manoore (2005), de Maria Daria Menozzi. Con el subtítulo Donne al lavoro nel tempo della globalizzazione, la directora cuenta la historia de una senegalesa, una brasileña y 
una malaya que nos hablan del derecho de las mujeres al trabajo en sus respectivos paises.

Emanuela Piovano se interesa por un período concreto de la historia italiana: la época de la resistencia antifascista. Sus investigaciones en el Archivo Nacional Cinematográfico de la Resistencia en Turín sobre el papel de las mujeres en esta época tienen como resultado la creación de la asociación Camera Woman para estimular y difundir los estudios sobre las mujeres. En el cine, esta inquietud por la mujer se manifiesta en una de sus primeras producciones: Le rose blu (1990), un documental donde realiza una serie de entrevistas a las reclusas de la cárcel Le Vallette de Turín.

Otro capítulo de la historia que afecta especialmente a las mujeres será el de la Inquisición, con sus constantes acusaciones y persecuciones a la mujer. Sobre este tema destaca el largometraje Processo a Caterina Ross (1982) de Gabriela Rosaleva. La directora se ocupa del juicio a Caterina Ross, acusada de brujería en el siglo XVII. También a una época pasada se remonta // resto di niente (2005), de Antonietta de Lillo, que rescata la figura de Eleonora Fonseca Pimentel, una revolucionaria liberal en la Nápoles del siglo XVIII. Se trata de una mujer transgresora, erudita, poeta y autora de diversos artículos sobre sociedad y política que incomodaron a los hombres de su época.

Otras directoras se han interesado por la mujer dentro de ámbitos que tradicionalmente le han sido vetados, como es el caso del ejército. A propósito de este argumento, Maria Martinelli dirige lo giuro-appunti di donne soldato (2007), donde se pone de manifiesto la valentía y la autodeterminación de las mujeres dentro de las fuerzas armadas. Dos años más tarde, la misma directora dirige Over the Rainbow (2009), un largometraje sobre una pareja de lesbianas que desea adoptar un niño. En este caso, hace hincapié en las dificultades de las dos mujeres, que se enfrentan a una serie de prejuicios aún presentes en la sociedad actual.

Con una fuerte implicación social, Isabella Ciarchi reproduce una entrevista a "le mamme del Leoncavallo", la asociación de madres antifascistas que lucha desde los años 90 por la paz y los derechos de los jóvenes. Así nace el cortometraje Le mamme del Leoncavallo, que presenta en 1994 en el XII Festival Internacional de Cine Joven.
Se evidencia, pues, que la representación de la mujer abarca todos los ámbitos: desde la historia a la política, de la lucha en la esfera pública a la condena de la represión en el espacio privado, de la reivindicación de los derechos de la mujer a la denuncia de los prejuicios existentes.

Esta multiplicidad de imágenes se extiende también a la literatura. Muchas directoras se han sentido atraídas por narradoras y poetisas italianas, como Marina Spada, que en su Poesia che mi guardi (2009) recrea la historia de la poeta Antonia Pozzi, nacida en Milán en 1912. Marina Spada recupera la figura de la poeta que, a pesar de su trágico final a los veintiséis años, ${ }^{2}$ legó a la historia de la literatura italiana versos de gran calidad artística.

La conexión entre el cine y la literatura de mujeres, entre las cineastas y las literatas, se evidencia, además, en las películas dirigidas por mujeres, inspiradas en novelas de escritoras. En Italia existen varios ejemplos de adaptaciones cinematográficas de novelas firmadas por mujeres, llevadas a la gran pantalla también por mujeres. Es como si se creara una hermandad de "donne" que une a literatas y a cineastas. Una unión que quizá surja de la comunión ideológica, de una misma mirada que hace congeniar la literatura femenina con el cine de mujeres. Podríamos citar, a modo de ejemplo, la película $V^{\prime}$ dove ti porta il cuore (1996) de Cristina Comencini, basada en la novela de Susanna Tamaro; la comedia La bruttina stagionata (1996) de Anna di Francisca, adaptación cinematográfica de la obra homónima de la escritora Carmen Covito, película con la que consigue la nominación al premio David di Donatello como mejor directora novel; el filme de suspense de Emanuela Piovano, Le complici (1993), inspirada en la obra Complice il dubbio de Maria Rosa Cutrufelli; o la película dirigida por Anna Negri, In principio erano le mutande (1999), adaptación de la novela de la escritora genovesa Rossana Campo.

Además de este interés por la mujer en todos los campos del arte, de la cultura, de la sociedad y de la historia, el cine femenino italiano posee otras peculiaridades que se repiten en todas las directoras. Entre éstas destaca la implicación de las cineastas en diversos trabajos del mundo cinematográfico (como guionistas, actrices o productoras) a expensas del trabajo de dirección, un hecho que muestra su gran versatilidad. Dentro del campo de la producción es importante el espíritu emprendedor de las cineastas, mu- 
chas de ellas fundadoras o cofundadoras de productoras de cine. Citamos, a modo de ejemplo, a Emanuela Piovano, creadora de la Kitchenfilm en 1988; a Roberta Torre, que en los años noventa es una de las fundadoras de Anonimi\& Independenti; a Luisa Petrolani, que funda PAHN Inc., con sede en Nueva York, y a Enza Negroni, que, junto a Renato De Maria, crea la productora Monocrome. Por otra parte, se trata de mujeres muy preparadas que en su gran mayoría se han formado o han completado su formación fuera de Italia, principalmente en Reino Unido y en Estados Unidos.

Son, en definitiva, características comunes de un cine cada vez más afianzado en Italia, que goza del reconocimiento de la crítica y del público, pero al que todavía le falta un largo camino por recorrer. Son aún muy pocas las mujeres que han sido premiadas con el David di Donatello, el premio de la Academia de cine italiano, o con el Nastro d'Argento. Desde 1980 solo tres directoras han recibido este galardón en la categoría de "dirección": Francesca Archibugi, ${ }^{3}$ Simona Izzo y Roberta Torre. Las tres en la sección de "mejor director novel". Este hecho pone de manifiesto que las mujeres continúan siendo un colectivo minoritario en cuanto a grandes reconocimientos y galardones, fundamentales para la promoción y la difusión de sus trabajos dentro y fuera de Italia. Esta falta de proyección de las cineastas no impide, sin embargo, que cada vez más mujeres se inicien en el mundo de la dirección con ilusión y empeño, a pesar de los obstáculos y barreras, testimoniando la riqueza de la mirada femenina y su incalculable valor dentro de la historia cinematográfica.

La siciliana Costanza Quatriglio es una de estas directoras cuya producción revaloriza y aporta frescura al cine italiano contemporáneo. Inicia su carrera a finales de los años noventa con la dirección de varios cortometrajes, entre ellos L'albero, de 1997; Anna, de 1998, que presenta en el festival de Cannes en 2000, o I/ giorno che ho ucciso il mio amico soldato, de 1999. La directora privilegia el género documental que se configura como uno de los rasgos característicos de su producción. Entre los documentales más notorios destaca Ecosaimale? (2000), galardonado con el premio del jurado en el Festival de Turín; L'insonnia di Devi (2001), II mondo addosso (2006), o II mio cuore umano (2009). A éstos se suma el largometraje L'isola (2003), una película ambientada en su tierra natal, Sicilia, que reproduce la historia de dos hermanos, Teresa y Turi, y su cotidianeidad infantil. Este filme catapulta la carrera de la directora, que consigue el reconocimiento de la crítica no solo nacional sino también internacional, con la distribución de su obra en Italia, Francia, Bélgica, Canadá y en varios paises hispanoamericanos. ${ }^{4}$

Quatriglio es una directora fiel a la tradición realista del cine italiano, que capta la realidad de forma estremecedora. Su temática abarca una serie de argumentos de actualidad entre los que se evidencia la predilección por su propia tierra y la vida cotidiana de sus habitantes, la infancia, la adolescencia y la inmigración. El tema de la inmigración es el común denominador de películas documentales como L'insonnia di Devi, II mondo addosso o RaízRadici a Capo Verde. En la primera nos muestra el mundo de las adopciones fuera de Italia, especialmente en paises subdesarrollados. En II mondo addosso plasma la historia de cuatro jóvenes inmigrantes, con sus vicisitudes diarias y su lucha continua para conseguir la permanencia en Italia. En Raíz la acción gira en torno a una familia caboverdiana asentada en Italia, centrándose en su cotidianeidad, en su integración, en sus anhelos y objetivos en el país de acogida. El documental se emitió en televisión, dividido en tres capitulos.

A estas producciones se suma La borsa di Helene, un minidocumental sobre Helene, una joven africana en Palermo. Su interés por la inmigración responde a la necesidad de reproducir en la ficción un tema de gran actualidad, que está transformando el modo de ser del italiano, que afecta a las costumbres y tradiciones más arraigadas, que suscita continuos debates sociales y políticos. Un tema, en definitiva, incandescente, polémico y controvertido que atiende a la realidad más inmediata del país. Se trata, según declara la directora en la entrevista que se reproduce a continuación, de "portare la gente dove non vuole andaré",

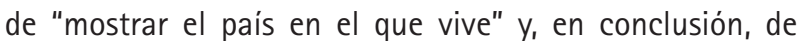
"hacer películas que muestren la vida". De esa implicación social nace su participación en el filme colectivo All Human Rights for All, treinta episodios inspirados en los treinta artículos de la Declaración universal de los Derechos del Hombre, una producción de Rai Cinema, retransmitido en RAI3 en 2008.

Por otra parte, destaca dentro de la producción de Quatriglio la atención a la infancia y a la adolescencia. Sin duda, los verdaderos protagonistas de sus largometrajes son los niños y adolescentes, como muestra en Ecosaimale?, sobre 
los jóvenes de un barrio palermitano, o en L'isola, la película de ficción con actores no profesionales sobre la infancia y la adolescencia de Teresa y Turi en su pequeño pueblo siciliano. De este largometraje nace Racconti per l'isola, un documental en el que la directora revela su método de trabajo en L'isola. Y también en el centro de la acción sitúa al pequeño Gioacchino en I/ bambino Gioacchino, una obra documental de veinticinco minutos cuyo único intérprete es Gioacchino.

Costanza Quatriglio es un claro ejemplo de la riqueza y éxito del cine de mujeres en Italia. La propia directora ha tenido la cortesía de desvelarnos algunos secretos de su producción y compartir una serie de ideas sobre el cine italiano contemporáneo y sobre la situación de las mujeres cineastas en su pais.

Reproducimos la traducción ${ }^{5}$ al español de nuestra conversación con la cineasta en mayo de 2011.

\section{Pregunta: Háblanos de tus inicios. Eres licenciada en derecho, ¿cómo surge tu interés por la dirección cine- matográfica?}

Costanza: Siempre he unido mi deseo de hacer cine con las ganas de contar historias. Cuando me he acercado al cine, inmediatamente lo he considerado un instrumento para decir cosas, más allá de mi gran pasión por el cine como lenguaje y como forma de arte. Paradójicamente, no habría podido elegir algo diferente, puesto que en los primeros años de mi carrera he intentado hacer películas que tuvieran conexión con las temáticas que había afrontado en el transcurso de mis estudios. Recuerdo que mi primer documental sobre las adopciones internacionales derivaba del estudio que había realizado para mi tesina sobre el derecho a la identidad. El filme es fruto de un largo trabajo sobre la cuestión; el tipo de trabajo que nunca habría podido hacer para mi tesina, lo he hecho después, transformando en una película los testimonios de adolescentes y adultos adoptados en Italia, oriundos de paises extranjeros. Ha sido televisado en Tele+ en un momento en el que en Italia no estaba muy difundido el tema de adopciones internacionales y las personas se sorprendian si veían a un chico indio hablar perfectamente en italiano. Desde entonces, han pasado diez años y las cosas han cambiado mucho en nuestro país, que está ajustando cuentas con la cada vez más creciente inmigración.

\section{P: ¿Cuál fue tu primer trabajo de dirección?}

C: Es difícil responder a esta pregunta porque cada película es como si fuera la primera. Cuanto más crece mi conocimiento y mi dominio del medio, más me gusta experimentar y aventurarme en nuevos terrenos, inexplorados, sobre todo desde el punto de vista del lenguaje y de la forma cinematográfica. Pero no es solo éste el motivo: en realidad, cada película es un exordio porque en Italia es difícil tener un camino profesional lineal. Se es considerado director joven hasta los cincuenta años $y$, normalmente, es difícil encontrar el terreno fértil para recoger cuanto se ha sembrado; en pocas palabras: siempre parece como si empezaras de nuevo. Volviendo a tu pregunta, mi primer filme como directora fue un cortometraje que recuerda los primeros años del cine mudo. Un tren que entra en la estación, una señorita con una maleta que va al encuentro de su amor, después se despierta y comprendemos que se trataba de un sueño. Era 1996. Inmediatamente después he hecho cortometrajes que intentaban explorar el aspecto figurativo de la historia. Antes de involucrarme en la realización de documentales, deseaba trabajar gráficamente sobre la realidad, abstrayendo los ambientes e imaginando personajes extremos, con una fuerte connotación simbólica. Los elementos, casi siempre, tenían una naturaleza mágica y el nivel narrativo se subordinaba a la eficacia figurativa y expresiva de la puesta en escena. Un ejemplo para todos: el cortometraje Anna!, realizado en el segundo curso de la academia de cine: en él, el blanco, el acero y el rojo son elementos imprescindibles y son la base del relato que narra una jornada de una obrera en un matadero, donde no se ven ni carnes ni animales; sin embargo, hay una continua alusión a éstos y a su muerte.

\section{P: ¿Quiénes han sido tus maestros dentro del mundo cinematográfico?}

C: Hay muchos directores que me apasionan. Cuando empezaba a interesarme por el cine, como a casi todos, me fascinaban los grandes maestros: Bergman, Truffaut, Godard, Bresson, pero también Kubrik, Kurosawa... Digamos que siempre me han gustado los directores que consiguen proponer una visión del mundo, aquellos directores que no se limitan a contar una historia, sino que tienen una visión precisa y son capaces de incidir en el ámbito cultural. 
Si hablo de conexión propiamente dicha, debo decir que ha sido fundamental, en mi formación, el conocimiento de Abbas Kiarostami. Lo conocí en 1996, antes incluso de ser admitida en la academia de cine. Aún vivía en Palermo y tuve la suerte de asistir a un taller de varios dias con él. Me encontré a mí misma en su modo de trabajar, algo que ha marcado profundamente mi carrera profesional en el uso del binomio realidad-ficción. No es casualidad que esto, después, se haya convertido en la clave de mi trabajo: la construcción de relatos de ficción a través de detalles de la realidad en los que los elementos de la narración se integran perfectamente con los elementos emocionales surgidos del trabajo con los actores. En el largometraje L'isola, por ejemplo, los detalles de la realidad, sobre todo la vivencia de los intérpretes y sus emociones, se han insertado en contextos de ficción al servicio de la historia; así como, viceversa, hay detalles de ficción insertados en contextos reales, cuando a un actor se le pide que forme parte de un mundo preexistente, como por ejemplo el de los pescadores durante las escenas de pesca del atún.

\section{P: Inicias tu carrera cinematográfica a una edad muy} temprana, consiguiendo el reconocimiento de la crítica en varios festivales internacionales. ¿Has encontrado dificultades para abrirte camino dentro del cine por tu juventud o por tu condición de mujer?

C: Desgraciadamente, la respuesta es sí. Si me hubieras hecho esta pregunta hace algún año, te habría dicho que no porque todavía estaba ilusionada con que en este país hubiera espacio para las personas jóvenes y para las mujeres. Pero, por desgracia, cuanto más pasa el tiempo, más me doy cuenta de que mis dificultades están todas ligadas al único hecho de ser mujer y joven. Porque hay en Italia un paternalismo difundido y generalizado por el que si una mujer joven demuestra tener talento, éste nunca es suficiente. Nunca es bastante. Es como si se nos pidiera ser unos superhéroes samuráis que se inmolan en una guerra que no ve nunca el final. Es una gran injusticia, y esto lo puedes verificar observando los datos estadísticos. En cualquier elenco de películas realizadas o por realizar en Italia, de cualquier año, notarás que las mujeres están en una proporción de tres sobre cuarenta. Es distinto en el caso del género documental, porque en los últimos años las mujeres han intentado mostrar este pais con un género que, desde el punto de vista de los productores, cuesta poco y toda la carga recae en quien lo hace. Perfecto, pues, para las mujeres... En Italia para hacer un documental hace falta tanto esfuerzo...

P: En efecto, dentro de tu producción ocupa un lugar fundamental el género documental. Más allá del apoyo de las productoras y del esfuerzo que supone, ¿a qué se debe la predilección por este tipo de cine?

C: Empecé a hacer documentales en cuanto pude. De algún modo, retomo la respuesta a tu primera pregunta: quiero hacer cine para contar historias. Me apasionan las personas, me apasiona poder contar la vida de las personas. $Y$ me gusta entrar en mundos diferentes al mío, explorarlos, ponerme a escuchar. De alguna forma, hacer un documental es una experiencia de vida. Solo poniéndose en juego se obtienen grandes resultados. Otra cosa que me gusta muchísimo del documental son las posibilidades narrativas. Me explico: me gusta construir la narración a partir de la propia realidad, reconstruyendo en una trama propiamente dicha el hilo de la historia. En este sentido, el guionista es el propio devenir de la realidad, el transcurso de los hechos de la vida ordenados cronológicamente; pero, sobre todo, emotivamente: escuchando la realidad y haciéndose guiar por ella, ésta se puede reorganizar en una trama capaz de emocionar, al igual que los sucesos de un filme de ficción. Para llegar a esto, el trabajo es larguísimo. Hace falta conciencia de la propia labor y responsabilidad del propio papel, una elección ética muy precisa: elegir de qué parte estar, el punto de vista, ser coherentes con ello y avanzar de modo claro, coherente con el objetivo.

\section{P: Podríamos decir que el tuyo es un documental social,} una definición que encuentra su justificación en la elección temática de tus producciones: siempre atenta a temas de actualidad como la inmigración, las adopciones en países subdesarrollados, la marginalidad o las clases más desfavorecidas de la sociedad. ¿Te consideras una directora comprometida con tu época?

C: Creo que, en general, una película documental es un instrumento excepcional para interrogarse sobre la realidad, sobre la condición de los seres humanos, y que la fuerza de las preguntas está en el hecho de que éstas sean formuladas en los lugares más difíciles de frecuentar, en los territorios más impracticables, en los incómodos, en los que hacen daño. Llevar a la gente donde no quiere ir. Éste ha sido, seguramente, el motivo creador de todos mis 
documentales. En este sentido, sí, soy una directora comprometida, puesto que sí quiero mostrar el país en el que vivo. Por ello, considero cada película una película política. Diría que el aspecto político es decisivo, entendido no como un eslogan que se consuma rápidamente, sino como meditación. Mi elección es siempre la de hacer películas que muestren la vida y, mostrando la vida, que sirvan como instrumento crítico para interpretarla.

P: Algunas de tus obras más conocidas están protagonizadas por niños y adolescentes, entre ellas Ecosaimale?, L'insonnia di Devi, II mondo addosso y el largometraje L'isola. ¿Por qué este interés por mostrar la vida de los más jóvenes?

C: Siempre me ha interesado explorar el momento de formación de uno mismo. Me atrae el tema de la búsqueda de identidad. Me gusta, además, fijar el momento de la vida en el que todo pasa, todo es dinámico, en el que uno se trasforma rápidamente. En este sentido, la infancia y la adolescencia son momentos privilegiados. Hoy en día, sin embargo, el que haga documentales debe ajustarse a un imaginario distinto al de hace diez años: la difusión de los reality shows en la televisión ha modificado radicalmente la percepción de uno mismo, por lo que hoy en día es necesario tener en cuenta el grandísimo deseo de auto-representación, propio del imaginario televisivo. Así pues, es tarea del narrador alejarse de ese deseo de auto-representación e intentar registrar en profundidad el sentido íntimo de las cosas.

P: Otro tema fundamental de tu producción es la inmigración, que retratas desde diversos puntos de vista en documentales como II mondo addosso o Raíz-Radici a Capo Verde. En ambas producciones se muestran las inquietudes y anhelos de los inmigrantes, sus objetivos y su lucha por la supervivencia en una Italia contradictoria, que no siempre refleja el paraíso imaginado. ¿Cuál es el motivo de tu atención al problema de la inmigración?

C: A decir verdad, me lo he preguntado muchas veces. Probablemente, por el hecho de sentirme yo -en primera persona- "ciudadana del mundo" y porque encuentro profundamente injusto el nacionalismo entendido como rechazo a los otros. Será, además, porque me gusta estar en aquel terreno intermedio que es la búsqueda, el deseo, el trabajo de la construcción de uno mismo, que para los inmigrantes se corresponde, naturalmente, con una condición existencial.

P: En I/ mondo addosso cuentas la historia de cuatro adolescentes inmigrantes que viven solos en Roma, mostrando su cotidianeidad y sus preocupaciones dentro de un país extranjero. ¿Cuál es la moraleja de esta obra?

C: En II mondo addosso he querido hacer una película sobre la Italia de hoy, narrando la historia de extranjeros jovencisimos que, entre las redes de la burocracia y de las políticas de acogida, se encuentran lidiando con la educación y la formación, derechos que a menudo se pierden al alcanzar la mayoría de edad. Me interesaba encontrar personas, no estadísticas: por eso, opté por contar momentos de formación que son, sobre todo, momentos emotivos propios de la edad de los chicos, que pertenecen a la construcción de uno mismo. El filme reproduce la cruel normalidad de la cotidianeidad de los adolescentes habituados a hablar de traficantes de vidas humanas, de viajes en la parte baja de los camiones, de compañeros muertos o desperdigados a lo largo del trayecto, como la escena en la que Mohammad Jan muestra a sus amigos la foto de un joven desaparecido, caído de un camión en marcha en una autovía quién sabe en qué lugar de Italia. En esa escena el espectador es introducido de una manera simple e inmediata dentro del mundo del miedo y de la negación de los derechos fundamentales.

P: En cuanto a tu producción más reciente, destaca el filme documental /I mio cuore umano, retransmitido en RAI3 en 2009. En las últimas décadas muchas directoras han encontrado en la literatura escrita por mujeres en Italia una importante fuente de inspiración para sus películas. Podríamos citar muchos títulos como Va' dove ti porta il cuore, dirigida por Cristina Comencini; La bruttina stagionata de Anna di Francisca; Le complici de Emanuela Piovano, y, más recientemente, L'iguana, de Catherine McGilvray. En tu caso, te has interesado por la novela autobiográfica de la conocida cantante Nada Malanima. ¿Qué es lo que te ha atraído de ella? ¿Por qué esta figura femenina?

C: Me ha entusiasmado la historia de la infancia de Nada: una niña de pueblo, en la Italia de los años cincuenta y 
sesenta, animada por su madre a asistir a clases de canto para valorar el don natural de una bonita voz. Es como "Bellissima" de Visconti: una madre volitiva y ambiciosa que quiere que su hija tenga éxito. Son los primeros años de la televisión italiana; como si Nada fuera la antecesora de tantas chicas, incitadas por sus madres a formar parte del mundo del espectáculo. Lo que hace que esta historia sea extraordinaria es la relación con su madre: la mujer alternaba momentos en los que estaba bien con momentos de depresión en los que siempre parecía que iba a morir de un momento a otro. En estos momentos, la niña tenía que ser cuidada por tías solteras, monjas bondadosas 0 viejecillas afectuosas, que conocían su difícil historia y la protegían. Por este motivo, he encontrado en esta historia todos los ingredientes de una fábula: el estupor por la belleza de la naturaleza, la simplicidad de la vida en el campo, el miedo de una niña de perder a su madre.

\section{P: Hemos hecho mención a una serie de directoras} italianas, algunas de gran éxito como Cristina Comencini y otras emergentes como Catherine McGilvray. Tu producción comienza en los años 90 , una década en la que se reafirma en Italia el papel de la mujer directora. ¿Hay alguna directora que haya marcado tu producción o por la que te hayas sentido especialmente atraída?

C: Una mujer directora que me encanta es Agnes Varda. Solo ahora me doy cuenta de que en la pregunta sobre los maestros no la he citado. Y, sin embargo, su película Senza tetto né legge ha sido fundamental en mi formación. La he visto y revisto cientos de veces. No excluyo que la visión de aquella película haya influido -mucho antes de conocer a Kiarostami- en ese modo de contar que toma prestado el lenguaje del documental también para las películas de ficción.

P: En el cine italiano, como en el español, son muchos más los nombres de directores que han pasado a la historia del cine que los de directoras. ¿Crees que en Italia hoy en día se podría hablar de paridad en el terreno cinematográfico?

C: Como decía anteriormente, en absoluto. El problema no es solo para las directoras, sino para todos los roles, excepto para las actrices, aunque solo si son jóvenes. En Italia resulta difícil, incluso, pensar en una protagonista adulta, quizá de mediana edad. Por otra parte, también tendria algo que decir en lo que respecta a las historias: ¿cuáles y cuántas son las películas en las que las mujeres no son las novias, o las mujeres, o las amantes, o las madres de un hombre?

\section{P: ¿Cómo definirías el estado actual del cine italiano?}

C: Dicen que ahora el cine italiano va bien. En realidad ha habido un momento bueno en el que el público ha respondido bien a algunas comedias muy naif, realizadas por personajes cómicos famosos para el público televisivo. La verdad es que en Italia falta una política industrial para el cine y la cultura, aunque ni siquiera se habla de ello. No existe el mercado porque no existe el pluralismo. Hay dos grandes bloques: Rai Cinema y Medusa. Por otra parte, la producción es prácticamente idéntica. Lo gracioso es que no podemos hablar de línea de producción porque todo depende de las circunstancias. Hoy quieren solo comedias, mañana dicen que las comedias ya no están bien y que tienen que financiar otras películas. En el cine italiano no hay programación, previsión; falta completamente la mirada al futuro. La vista hacia la construcción de algo que dure en el tiempo, en el compromiso de todos. Incluso en lo que respecta a la distribución. Como solo hay dos grandes distribuidoras, distribuyen casi todas las películas que salen. Así pues, si un filme no genera mucha expectación el primer fin de semana, ¿ellos qué hacen? Lo quitan para dar espacio a otra película de su propia lista; de este modo eliminan la posibilidad de esa película de ganarse su propio público a lo largo del tiempo. En definitiva, no tengo una palabra clave para decir cuál es la situación del cine italiano, sé únicamente que así no se va a ninguna parte y que un país que no consigue hablar de sí mismo es un país muerto, de la misma manera que pienso que si una cinematografía no habla de su propio país, entonces es una cinematografía muerta.

P: Volvamos a tus inicios y, en concreto, a tus orígenes. Sucede en la literatura y también en el cine que se crea una hermandad insoslayable entre la tierra siciliana y la producción artística. Sicilia es el escenario de gran parte de tus producciones y es, sin duda, una de las principales fuentes de inspiración de tu cine. ¿Podrías decirnos qué hay de siciliano en tu arte?

C: De siciliano hay, seguramente, lo físico. Me entusiasman los cuerpos, los rostros. Me gustan las caras, las expresio- 
nes, los gestos. Me gusta sentir el perfume o el hedor de los lugares que filmo. Me considero una directora "física". De la misma manera que he dicho siempre que mis primeros documentales en Palermo eran "películas de calle", digo también que, en ciertos aspectos, para mí el cuerpo es todo. También me gusta la lengua, el sonido de la lengua, cuando ésta significa pertenencia. La lengua madre, la que determina nuestro yo más profundo, ya sea afgano o siciliano. Sí, justo eso: la lengua y los cuerpos.

\section{P: Concluimos con una mirada al futuro: ¿cuáles son tus proyectos futuros? ¿Para cuándo el próximo estreno?}

C: En este momento estoy terminando dos películas de diferente naturaleza. Una es un documental inspirado en la novela Terra Matta de Vincenzo Rabito, analfabeto siciliano que en los años setenta robó "literalmente" una máquina de escribir y reescribió toda la historia del siglo XX desde su punto de vista. Habiendo nacido en 1899, cuenta en primera persona la historia del hambre de los primeros años del siglo, después de la Gran Guerra, del colonialismo, de la Segunda Guerra Mundial, y así sucesivamente hasta la liberación, con la escolarización de sus tres hijos varones que hoy en día son ancianos. Lo interesante es que, siendo analfabeto, escribió mil páginas completas, inventándose una lengua que no era ni italiano ni siciliano, sino que, en realidad, era una lengua oral. Basta pensar que al no conocer el espaciado, las palabras están todas pegadas, divididas solo por un punto y coma. Después, el texto fue publicado por la editorial Einaudi, convirtiéndose en objeto de estudio de historiadores y lingüistas.

Otro proyecto que para mí es importantísimo, que estimo, es un "docu-fiction" basado en una historia real acaecida en Italia. Una historia llena de dolor que abre una brecha en el estado de las universidades italianas. Será una película de una hora y media, que se retransmitirá por la tarde en Rai Tre.

También estoy trabajando en el que será mi próximo largometraje para el cine... pero sobre este largo, para no gafarlo, no quisiera decir nada más.

\section{NOTAS:}

1 Directora húngara de nacimiento, pero italiana de formación, cuya producción se considera dentro del corpus cinematográfico italiano.

2 Antonia Pozzi muere por suicidio en 1938.

3 Francesca Archibugi será galardonada en tres ocasiones con el premio David di Donatello: en 1989 en la categoria "Mejor director novel" por la película Mignon è partita; en 1991 en la categoría "Mejor película" por Verso sera y en 1993 a la "Mejor película" por Il grande cocomero.

4 L'isola participa en casi cien festivales internacionales (Chicago, Pusan, Jerusalén, Nueva York, Kiev, Philadelphia, Boston, Rotterdam, Parí, Cairo, Montreal, San Francisco, Cuenca, Burdeos, Buenos Aires, Montpellier, Bratislava, Los Ángeles Int. FF, etc.) y obtiene numerosos premios, entre ellos el Premio
Cicae en Francia, Main Prize Fipresci en el festival de Bratislava, Cultural Grant Asia-Europe Foundation en el festival de Pusan en Corea del Sur, premio al mejor guión en el festival de Cuenca en Ecuador, y Nastro d'Argento en 2004 por la música del trompetista de jazz Paolo Fresu.

5 Entrevista original en lengua italiana. Traducción a cargo de la autora del artículo.

\section{FILMOGRAFÍA}

All Human Rights for All (Varios directores, 2008).

Anna (Dir. Costanza Quatriglio, 1998).

Bellissime-dal 1960 ad oggi dalla parte di "Lei" (Dir. Giovanna Gagliardo, 2006).

Bellissime. Il Novecento dalla parte di "Lei" (Dir. Giovanna Gagliardo, 2004).

Ecosaimale? (Dir. Costanza Quatriglio, 2000).
Aceptado: 30 de julio de 2011 
Il bambino Gioacchino (Dir. Costanza Quatriglio, 2000).

II giorno che ho ucciso il mio amico soldato (Dir. Costanza Quatriglio, 1999).

Il grande cocomero (Dir. Francesca Archibugi, 1993).

II mio cuore umano (Dir. Costanza Quatriglio, 2009).

Il mondo addosso (Dir. Costanza Quatriglio, 2006).

Il resto di niente (Dir. Antonietta de Lillo, 2005).

In principio erano le mutande (Dir. Anna Negri, 1999).

lo giuro-appunti di donne soldato (Dir. Maria Martinelli, 2007).

L'albero (Dir. Costanza Quatriglio, 1997).
L'insonnia di Devi (Dir. Costanza Quatriglio, 2001).

L'isola (Dir. Costanza Quatriglio, 2003).

La borsa di Helene (Dir. Costanza Quatriglio, 2002).

La bruttina stagionata (Dir. Anna di Francisca, 1996).

Le complici (Dir. Emanuela Piovano, 1993).

Le mamme del Leoncavallo (Dir. Isabella Ciarchi, 1994).

Le rose blu (Dir. Emmanuela Pioviano, Anna Gasco y Tiziana Pellerano, 1990).

Manoore (Dir. Maria Daria Menozzi, 2005).

Mignon è partita (Dir. Francesca Archibugi, 1989).

Over the Rainbow (Dir. Maria Martinelli, 2009).
Poesia che mi guardi (Dir. Marina Spada, 2009).

Processo a Caterina Ross (Dir. Gabriela Rosaleva, 1982).

Racconti per l'isola (Dir. Costanza Quatriglio, 2003).

Raíz-Radici a Capo Verde (Dir. Costanza Quatriglio, 2004).

Senza tetto né legge (Dir. Agnes Varda, 1985).

Va' dove ti porta il cuore (Dir. Cristina Comencini, 1996).

Verso sera (Dir. Francesca Archibugi, 1991).

Vogliamo anche le rose (Dir. Alina Marazzi, 2008). 